Notfall Rettungsmed 2011 · 14:303-304

DOI 10.1007/s10049-011-1440-1

Online publiziert: 26. Mai 2011

(c) Springer-Verlag 2011
D. Biarent · R. Bingham · C. Eich · J. López-Herce · I. Maconochie

A. Rodríguez-Núñez $\cdot$ T. Rajka $\cdot$ D. Zideman

\section{Erratum zu: Lebensrettende Maßnahmen bei Kindern („paediatric life support“)}

\author{
Sektion 6 der Leitlinien zur Reanimation 2010 \\ des European Resuscitation Council \\ Notfall + Rettungsmedizin (2010) 13:635-664 \\ DOI 10.1007/s10049-010-1372-1
}

Der Algorithmus „Erweiterte lebensrettende Maßnahmen beim Kind" (• Abb. 9 , S. 651) des oben genannten Beitrags wurde präzisiert.

Wir bitten, dies zu entschuldigen und die korrigierte Abbildung zu berücksichtigen.

\section{Korrespondenzadressen der verantwortlichen Herausgeber Univ.-Doz. Dr. M. Baubin}

Department Notfallmedizin, Universitätsklinik für Anaesthesie und Allg. Intensivmedizin Anichstraße 35, 6020 Innsbruck Österreich

michael.baubin@uki.at

\section{Dr. Dr. B. Dirks}

Sektion Notfallmedizin, Klinik für Anästhesiologie, Universitätsklinikum Ulm Prittwitzstraße 43, 89070 Ulm burkhard.dirks@uni-ulm.de
Erweiterte lebensrettende Maßnahmen beim Kind (Paediatric Life Support, PLS)

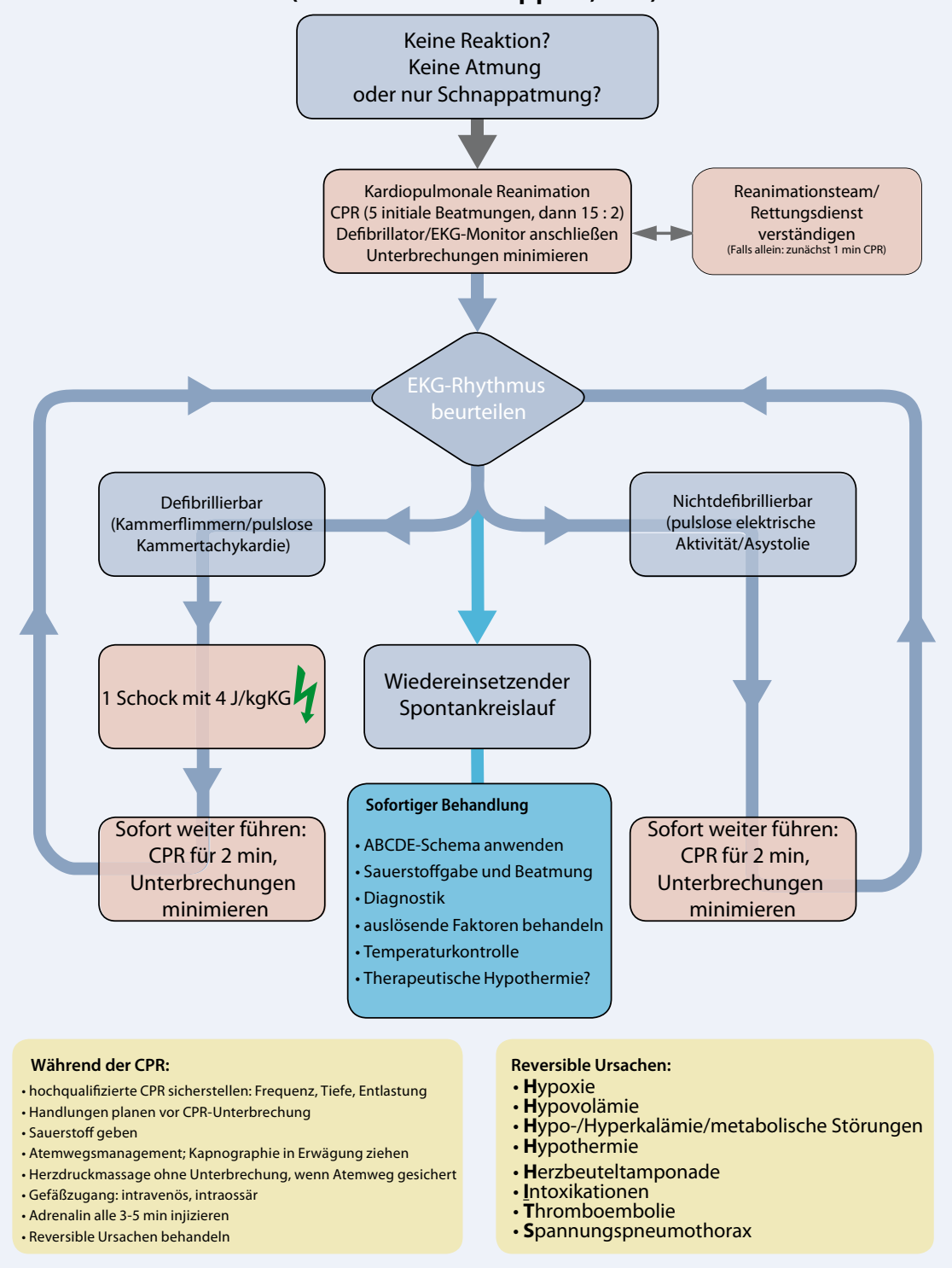

Abb. $9 \Delta$ Erweiterte lebensrettende Maßnahmen beim Kind. PEA pulslose elektrische Aktivität 


\section{Hier steht eine Anzeige.}

第 Springer 